\title{
土木工程施工中边坡支护技术探讨
}

\author{
孟小花* \\ 园城实业集团有限公司, 山东 264000
}

摘 要: 边坡技术是土木工程在施工初期过程中的一项工程项目。近些年, 我国经济的发展水平越来越高, 人民 的生活质量也在不断的提升, 对于建筑安全的要求也更加严格。而边坡技术的应用, 能够有效的提升项目施工过程中 的安全性, 减少建筑项目在运行过程中可能会出现的危险。所以, 在制定边坡支护方案时, 需要施工单位对施工环境 进行充分的了解与把握后，再进行详细的边坡支护方案制定，以确保在施工过程中对施工安全起到有效的保障作用。

关键词: 土木工程; 施工过程中; 边坡支护技术

\section{Discussion on Slope Support Technology in Civil Engineering Construction}

\author{
Xiao-Hua Meng* \\ Yuancheng Industrial Group Co., Ltd., Yantai 264000, Shandong, China
}

\begin{abstract}
Slope technology is an engineering project in the early stage of civil engineering construction. In recent years, the level of economic development in China has become higher and higher, the quality of life of the people has been continuously improved, and the requirements for building safety have become stricter. The application of slope technology can effectively improve the safety of the project during construction and reduce the dangers that may occur during the operation of the construction project. Therefore, when making a slope support plan, the construction company needs to fully understand the construction environment, and then develop a detailed slope support plan to ensure effective protection of construction safety during the construction process.
\end{abstract}

Keywords: Civil engineering; construction process; slope support technology

\section{一、前言}

成熟的边坡支护技术在整个土木工程中，对于工程的稳定性有着重要的作用和影响。因为在进行土木工程施工过 程中，土木工程项目的边坡往往要承受着巨大的重量，这就会造成土木工程项目的整体结构被下压。

做好边坡支护工作, 能够减少和避免因在施工过程中, 因边坡防护工作不佳而造成的下压问题以及其他严重后 果。因此本文将针对在土木工程施工过程中, 土木工程边坡防护工作存在的问题进行分析, 并针对相关问题提出实质 性的解决方案。

\section{二、对于土木工程施工过程中边坡支护技术方法简述}

在进行土木工程施工过程中，常用的土木工程边坡支护技术方法有以下三种。

(一) 地下连续墙技术

地下连续墙技术是通过在土木工程项目周边进行深挖沟槽, 并向沟槽之中注人混凝土泥浆, 所形成的一堵地下混 凝土连续墙, 从而达到对土木工程项目进行支护，防渗漏，阻拦水，承担土木工程项目边坡重量的作用和目的 ${ }^{[1]}$ 。

(二) 针杆支护技术

针杆支护技术是通过针杆与挡土墙结构的组合, 使针杆能够对结构物进行上托力、拉拔力、侧倾力等结构力, 起 到分担的作用，以确保土木工程项目边坡的稳定 ${ }^{[2]}$ 。

(三) 土钉墙支护技术

“通讯作者：孟小花，1984年10月，女，汉族，山东烟台人，现任园城实业集团有限公司项目管理公司总经理， 中级工程师, 本科。研究方向: 项目管理。 
如图1所示，土钉墙支护技术是通过在土木工程项目周边地基进行土钉体的插人，并且土钉在排列方面较为密 集, 然后再进行全孔注浆封填, 而形成的一堵土钉墙 ${ }^{[3]}$ 。施工单位在土木工程施工过程中, 对于土木工程边坡支护技 术的选择上, 要根据施工环境和施工要求进行不同的选择。比方说, 地下连续墙边坡支护技术对于土木施工地质的要 求不高, 在地址状况复杂以及土质松软的地区, 都能够进行地下连续墙边坡支护技术的使用, 并且能够起到稳固建筑 基础的作用。

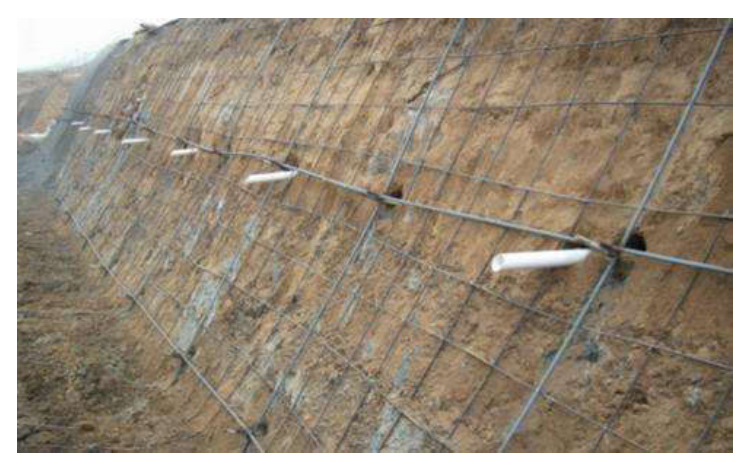

图1 土木工程项目土钉墙边坡支护技术施工现场

针杆边坡支护技术在土木工程项目中的应用具有一定的局限性，因为针杆边坡支护技术能够帮助建筑物分担上托 力、拉拔力、侧倾力等结构力的重量, 所以, 在进行针杆边坡支护技术方案的制定时, 对于锚杆边坡支护技术相关数 据的设置, 要参考墙壁涂压力、内柱、毛干的内力等, 作为锚杆边坡技术方案计算和参考的数据, 并且对于新填土的 方边坡, 如果高度大于 6 米, 则施工单位不能使用错杆支护技术作为土木工程边坡支护方法, 因为过于松软的土质和 过高的高度，会影响锚杆的抓力和稳固性。

土钉墙支护技术虽然在土木工程边坡支护应用时，具有较高的稳定性，但是土针墙支护技术对于施工环境具有较 高的要求, 需要施工单位了解清楚此项支护技术是否与当前土木工程项目施工环境相适宜, 再进行边坡支护方案的选 择和设计 ${ }^{[4]}$ 。

\section{三、浅析土木工程施工过程中边坡支护技术存在的问题}

现代土木工程施工过程中，造成边坡支护技术存在问题的主要原因有以下两点。

（一）缺少全面、前瞻性的考量与设计

施工单位在进行土木工程边坡支护技术方案的设计时，没有进行全面性、前瞻性的考量与设计，造成在土木工程 项目施工过程中, 因为边坡支护技术方案的设计不科学, 导致土木工程项目边坡的铺推面积不合理, 引发因边坡防护 措施不到位而产生的土木工程项目安全问题。因为施工单位在最初设计土木工程项目边坡支护技术方案时不够科学、 合理，这也会引发施工材料，施工工人数量配置不符合规定和要求的现象发生。

土木工程项目中边坡支护技术的应用，不仅是为了保证在施工过程中，加强建筑的稳固性和安全性，对于土木工 程建设后期也起到重要的作用 ${ }^{[5]}$ 。但是, 很多施工单位在进行最初土木工程项目边坡技术方案设计时, 没有考虑到更 加长远的发生和更多不确定性因素的影响, 导致土木工程项目边坡支护技术方案不完整, 就有可能会引发坍塌、滑坡 等不确定性结果的发生。所以, 这就要求施工单位在进行土木工程项目施工前要进行长远的打算, 以发展的眼光去看 待和进行土木工程项目边坡支护技术方案的设计, 以防止和避免因相关不确定性因素，而导致土木工程建设的损坏， 造成不必要的损失。

（二）同一项目中存在多个施工队，造成开工时间不同步

在土木工程项目施工的过程中, 会有不同的施工队来完成不同的施工项目, 这也就导致土木工程项目内的施工项 目, 开工时间的不同 ${ }^{[6]}$ 。比方说, 在进行土木工程建筑时, 应先进行土木工程边坡支护技术的施工, 再进行土层开挖 工作。但是, 很多土木工程项目内的土方施工单位, 为了抢先工程进度进行提前施工, 阻碍和破坏了土木工程边坡支 护施工工作的进行, 导致边坡支护技术无法在土木工程项目实施过程中起到安全保障的作用, 并且有的边坡支护施工 单位为了节约时间和工程成本, 甚至会采用二次回填和搭设架子来完成土木工程边坡之户技术的施工, 违背了土木工 程项目的施工规定，为安全事故的发生埋下了隐患 ${ }^{[7]}$ 。 


\section{四、提升土木工程施工过程中边坡支护技术的应用探讨}

（一）实地考察施工环境，因地制宜制定工程边坡支护方案

土木工程建设项目中, 施工单位在进行土木工程边坡支护技术方案设计前, 施工单位要对施工项目的地点进行实 地考察, 根据施工环境的条件和要求, 进行相应的边坡支护技术方案的设计和选择。通过对土木工程项目周边环境的 资料收集和整理，在进行边坡支护技术方案设计的时候，需要对土木工程项目边坡的性质、易造成项目边坡失稳的机 理原因、土木工程项目的整体经济性等原因进行综合的考量，确保土木工程项目边坡支护技术方案能够在实施过程中 顺利进行。

比方说, 施工单位在接到土木工程项目的时候, 通过实地考察和研究, 确定了这项土木工程建设需要运用土钉墙 边坡支护技术来进行边坡保护工作, 施工人员在设计土钉墙边坡支护方案时, 就需要从土钉插人地基的深度, 土钉墙 对于土木工程项目边坡的支护强度，边坡支护技术施工人员的专业水平以及施工单位对于边坡支护的施工要求等方面 进行综合的设计。

在方案设计过程中, 对于已经形成插孔的编号、插孔位置, 施工人员要进行准确的标记, 以确保施工单位在土木 工程项目施工的过程中方便识别。为了确保土钉墙对土木工程项目边坡具有有效的保护性，还需要通过第三方进行拉 拔实验的方法, 加强土钉墙边坡支护项目的工程质量。当土钉墙的前期工作准备完毕，要进行最后的混凝土注浆时， 设计方案中要明确规范出注浆比例以及对外加剂用量的比例, 确保土钉墙的稳固性, 并且在进行注浆时, 通常会采用 的注浆方式是通过重力进行全孔式注浆封填, 当遇到特殊情况时, 也会通过补浆的方式作为土钉墙边坡支护技术的注 浆方法 ${ }^{[8]}$ 。

当土木工程项目边坡支护技术方案确定后, 施工单位仍需要在施工前与技术人员一起，对现场施工图纸、边坡支 护方案和图纸进行仔细的研究、分析和比对, 确保土木项工程项目在施工过程中能够顺利的进行, 施工单位在进行 图纸方案的对照时, 如发现不符合现场施工环境、施工条件的问题时, 要及时反映并进行修改, 不能为了追赶工程进 度，而忽视掉检查的重要性，更不能因为怕麻烦，而忽视问题的出现。

（二）加强土木工程项目中边坡支护技术的质量管理，提升施工人员的技术水平

在土木工程项目施工过程中, 想要加强土木工程边坡支护技术的质量, 就需要在土木工程项目施工前与土木工程 项目施工的过程中，对边坡支护技术的质量进行控制和管理。

1. 在进行土木工程边坡支护项目施工之前

施工单位需要明确目前进行施工的地点的土质特性，以保证在进行边坡支护技术方案设计的过程中，能够针对土 地的特性进行相应的设计, 对于土木工程中土质的优点进行发挥, 对于土质可能会给边坡支护施工带来的劣势, 要进 行相应的规避，并且通过对土质特性的了解和掌握，能够大大降低对于土质的破坏，为后期的基坑开挖工作带来有力 的保证。施工单位在进行土木工程施工前, 要保证用料和设备的数量能够满足施工过程中的基本需要, 并且在人员配 备数量上也要达到相应的规定和要求，来确保土木工程项目的施工质量。

2. 施工过程中

边坡支护技术的质量控制工作较为复杂和多变，为了提升边坡支护工程在施工过程中的安全性，保证工程施工效 率。施工单位需要要求施工现场的负责人员对现场环境要进行及时的清理, 保证现场环境的秩序性。在进行工作交接 时要，确保工作的衔接性，防止因技术交底工作不到位，导致施工程序交叉进行的现象发生。

施工单位要通过相关制度规范的确立和完善, 保证土木工程项目中边坡施工的质量和安全, 加强对于边坡施工技 术人员的专业性要求。可以通过短期的技术探讨以及定期的技能培训这样的方式，不断加强工程技术人员的能力和个 人素质, 并且要求在施工过程中, 对于施工技术的需要以及土木工程的建设标准, 要严格遵守我国土木工程建设的相 关法律法规，进行科学、合理的施工。

为了加强土木工程边坡支护施工的质量，施工单位可以组建相关的监督部门，对土木工程边坡支护项目进行监 督, 确保在土木工程施工前能够做好预防工作, 在土木项目施工过程中能够做好控制工作, 在土木工程项目施工完成 后能够做好改进工作。

（三）分区式开展基坑挖掘工作，善于利用边坡监测手段规避地质风险的发生

近些年，在土木工程项目中，我国的边坡支护施工单位为了保护土木工程环境中的地质结构和涂层结构，在开挖 
基坑的过程中不被破坏、保持平衡。发明了通过分区的方式对土木工程项目中基坑进行挖掘的方法, 保证了土木环境 工程环境中地质结构和土层结构的平衡, 并为基坑挖掘的工程后期提供了有利的环境和条件。在传统的土木工程项目 开挖基坑过程中, 因为是整片式的开挖, 所以, 对于基坑的基础平衡无法做到有效的保证, 这就会导致土木工程环境 中的地质结构和土层结构遭到严重的破坏。一旦土木工程环境中地质结构和土层结构遭到破坏, 对于基坑挖掘工程后 期就会出现变形和移位等现象的普遍发生, 为土木工程项目开挖基坑工作提升了难度, 也拖延了土木工程项目进行的 时间。而分区式开挖基坑的方法, 不仅能够保证土木工程环境中地质结构和土层结构的平衡, 并且对于开挖基坑的质 量也能够得到有效的保证和控制。

分区式开挖基坑的工作原理是在开槽后对需要开挖机坑的区域, 进行有效的支撑, 确保该区域内地质结构和土层 结构的稳定, 以及基坑基础的平衡后进行挖掘工作。在进行土木工程项目边坡支护施工的过程中, 会由于地质风险而 造成施工质量的不稳定性。所以, 边坡支护施工单位可以通过地质监测技术的应用, 对基坑挖掘地区的内部结构进行 检测, 加强表坡支护施工过程中的监测。一旦出现边坡失稳滑动和边坡变形的情况, 施工人员能够在第一时间知晓并 及时制定相应的解决方案。

\section{五、结语}

边坡支护技术作为土木工程项目中的基础工作, 对于土木工程项目的整体建设有着决定性的意义和作用。所谓 “万丈高楼平地起” , 只有做好基础工作, 才能够保证整个土木工程项目能够不断稳定、快速地向上迈进。所以, 施 工单位要不断重视和意识到边坡支护技术, 对于整体土木工程项目的开展实施的重要性, 并不断加强边坡支护技术的 应用方法的使用和质量控制, 提升土木工程项目建设的安全性, 加强对于边坡支护技术的研究分析, 不断创新技术, 使得边坡支护技术能够在土木工程的应用中发挥其重要性和积极作用。

\section{参考文献:}

[1]魏信飞.略谈土木工程施工中边坡支护技术的应用[J].江西建材, 2019(12):149+151.

[2]马元斌.提升土木工程施工中边坡支护技术的应用研究[J].住宅与房地产, 2019(36):207-208.

[3]王梓龙.提高土木工程施工中边坡支护技术的应用研究 [J].河南建材, 2020(01):20-22.

[4]吴冰.加强土木工程施工中边坡支护技术的运用方法研究[J]. 中外企业家, 2019(35):97-98.

[5]高云.提高土木工程施工中的边坡支护技术的应用探讨[J].花炮科技与市场, 2019(04):114+116.

[6]丁旭.加强土木工程施工中边坡支护技术的应用研究[J].居舍, 2019(31):35-36.

[7]熊国夫.提高土木工程施工中的边坡支护技术要点分析[J].现代物业(中旬刊), 2019(08):185-186.

[8]朱云峰.加强土木工程施工中的边坡支护技术的应用研究[J].绿色环保建材, 2019(07): 152+155. 